\title{
Bending instability of few-layer graphene embedded in strained polymer matrix
}

\author{
Yu. A. Kosevich ${ }^{1,2,}$, A. A. Kistanov ${ }^{3}$, I. A. Strelnikov ${ }^{1}$ \\ †yukosevich@gmail.com
}

\begin{abstract}
${ }^{1}$ Semenov Institute of Chemical Physics of RAS, 4 Kosygin str., Moscow, 119991, Russia ${ }^{2}$ Plekhanov Russian University of Economics, 36 Stremyanny per., Moscow, 117997, Russia ${ }^{3}$ Institute for Metals Superplasticity Problems of RAS, 39 Khalturina str., Ufa, 450001, Russia
\end{abstract}

In this Letter we describe analytically and simulate numerically the softening of flexural surface acoustic waves, localized in the plane of few-layer graphene embedded in soft matrix of low-density polyethylene. The softening of surface acoustic wave is triggered by the compressive strain in the matrix, which results in compressive surface stress in the few-layer graphene. Softening of the flexural surface acoustic wave leads to spatially periodic static bending deformation (modulation) of the embedded nanolayer with the definite wave number. Few-layer graphene with different numbers of graphene monolayers is considered. We describe the different models of interlayer bonding of graphene monolayers in a few-layer graphene, which correspond to the weak and strong interlayer bonding. The considered models give substantially different scaling of the wave number of periodic bending deformation and of the threshold compressive strain in the matrix as functions of the number of graphene monolayers in the few-layer graphene. Both the wave number of periodic bending deformation and the values of the threshold compressive surface stress in the few-layer graphene and of the compressive strain in the matrix are very well confirmed by the numerical simulations. Bending instability of few-layer graphene can be used for the study of bending stiffness and two-dimensional Young modulus of the graphene nanolayers, embedded in a soft matrix.

Keywords: few-layer graphene, bending stiffness, two-dimensional Young modulus, bending modulation wavelength.

УДК: 547.022.1/.46, 661. 66: 620.5.

\section{Изгибная неустойчивость многослойного графена в матрице из деформированного полимера}

\author{
Косевич Ю. А. ${ }^{1,2, \uparrow}$, Кистанов А. А. ${ }^{3}$, Стрельников И. А. ${ }^{1}$ \\ ${ }^{1}$ Институт химической физики им. Н. Н. Семёнова РАН, ул. Косыгина, 4, Москва, 119991, Россия \\ ${ }^{2}$ Российский экономический университет имени Г. В. Плеханова, Стремянный пер., 36, Москва, 117997, Россия \\ ${ }^{3}$ Институт проблем сверхпластичности металлов РАН, ул. Ст. Халтурина, 39, Уфа, 450001, Россия
}

Дано аналитическое описание и проведено численное моделирование смягчения изгибных поверхностных акустических волн, локализованных на плоскости многослойного графена, встроенного в мягкую матрицу из полиэтилена низкой плотности. Показано, что смягчение поверхностной акустической волны вызвано деформацией сжатия в матрице, которая приводит к компрессионному поверхностному напряжению в многослойном графене. Смягчение изгибной поверхностной акустической волны приводит к пространственно-периодической деформации статического изгиба (модуляции) встроенного нанослоя с определенным волновым числом. В работе рассмотрен многослойный графен с разным числом слоев. Описаны различные модели межслоевого взаимодействия графеновых монослоев в многослойном графене, которые соответствуют слабым и сильным межслоевым взаимодействиям. Рассмотренные модели дают существенно различные зависимости волнового числа периодической изгибной деформации и пороговой деформации сжатия в матрице от числа слоев в многослойном графене. Численное моделирование очень хорошо подтверждает как волновое число периодической деформации изгиба, так и пороговое компрессионное поверхностное напряжение в многослойном графене и пороговую деформацию сжатия в матрице. Изгибная неустойчивость многослойного графена может быть использована для изучения изгибной жесткости и двумерного модуля Юнга графеновых нанослоев, встроенных в мягкую матрицу.

Ключевые слова: многослойный графен, изгибная жесткость, двумерный модуль Юнга, длина волны модуляции изгиба. 


\section{Introduction}

Outstanding mechanical properties of graphene have made it very attractive for the construction of nano- and electro-mechanical devices and in composite materials [1]. Elastic properties of graphene have been measured using nanoindentation [2] and pressurization [3] techniques, and the Young modulus $E_{s}$ of two-dimensional (2D) elastic layer was found to be extremely high, $E_{s}=\rho_{s} v_{l}^{2} \sim 22 \mathrm{eV} / \AA^{2}$, where $v_{l}=21.6 \mathrm{~km} / \mathrm{s}$ is longitudinal sound velocity and $\rho_{s}=7.6 \times 10^{-7} \mathrm{~kg} / \mathrm{m}^{2}$ is mass density per unit surface area [4]. Nevertheless, the mechanical interplay between mono- and few-layer graphene and other materials is not well studied, although it is crucial for the use of graphene in composite [1], flexible, and strain-engineered [5] materials. Low value of graphene bending stiffness allows for easy formation of secondary structures including wrinkles, scrolls and folds [6-10].

In Ref. [11] it was predicted the softening of the flexural surface acoustic wave, localized at the graphene monolayer, caused by negative (compressive) surface stress $g_{x x}$ and finite bending stiffness $D_{s}$ of the 2D elastic layer. Softening of the flexural surface acoustic wave results in periodic static bending deformation (modulation) of the interface layer with the definite wave number $k_{x 0}$ of the monolayer, embedded in a strained matrix. This effect can be triggered, e.g., by the compression of the solid along the $x$ axis, which results in the compressive strain and negative surface stress $g_{x x}$ in the embedded graphene monolayer. The softening of the flexural surface acoustic wave in a sandwich-like elastic structure presents a dynamical counterpart of purely static phenomenon of the buckling of the plate sandwiched in the compressively strained matrix (see, e.g., Ref. [12]). The possibility of the softening of surface acoustic Rayleigh and interface waves, triggered by negative surface stress, was noted in $[13,14,15]$.

In this Letter we describe the bending instability of the few-layer graphene (FLG) embedded in a strained polymer matrix. The threshold matrix strain and bending modulation wavelength are determined by the bending stiffness and Young modulus of the 2D elastic layer, and by the shear modulus and ratio between transverse and longitudinal bulk velocities in the matrix [11]. The main difference from the monolayer graphene is the dependence of the bending stiffness and Young modulus of the $2 \mathrm{D}$ elastic layer on the number of carbon layers in or on effective thickness of the few-layer graphene. In the case of continuous macroscopic layer, the bending stiffness grows with the layer thickness $h$ as $D_{s} \sim h^{3}[16,17]$, while $E_{s} \sim h$, which corresponds to the strong interlayer bonding in the layer. Another model of FLG is based on the fact that the bonding between the carbon monolayers is provided by relatively weak van der Waals interaction while the bending stiffness and 2D Young modulus of the elastic nanolayer are determined by more strong covalent bonding and three-body Keating-type potentials $[18,19,20]$. In this model of weak interlayer bonding in FLG, both the bending stiffness and 2D Young modulus of the elastic nanolayer are considered to be given by the number of graphene monolayers $n, D_{s}^{(n)}=n D_{s}, E_{s}^{(n)}=n E_{s}$, see, e.g., [21].

\section{Model}

To describe the softening of the flexural surface acoustic wave in the plane of FLG, triggered by negative (compressive) surface stress, we start with the dispersion equation for the surface wave with the quasi-transverse polarization, normal to the nanolayer plane, see [11]:

$\left(q_{1}+q_{2}\right) q_{2} C_{11} C_{66}=\frac{1}{2}\left(\rho_{s}-g_{x x} k_{x}^{2}-D_{s} k_{x}^{4}\right)\left(C_{11} q_{1}+C_{66} q_{2}\right)$,

where in the isotropic polymer solid one has $q_{1}=\sqrt{k_{x}^{2}-\omega^{2} / v_{l}^{2}}, \quad q_{2}=\sqrt{k_{x}^{2}-\omega^{2} / v_{t}^{2}}, \quad v_{l}=\sqrt{C_{11} / \rho} \quad$ and $v_{t}=\sqrt{C_{66} / \rho}$ are velocities of longitudinal and transverse elastic waves in polymer matrix, $C_{11}=\lambda+2 \mu$ and $C_{66}=\mu$ are the elastic moduli, with $\lambda$ and $\mu$ being the Lamé coefficients of polymer solid.

The value of the negative surface stress $g_{x x}=-\left|g_{x x}\right|$ and the wavenumber $k_{x 0}$ at which the softening occurs can be found from the following two conditions,

$$
\omega\left(k_{x 0}\right)=0, \frac{\partial \omega\left(k_{x 0}\right)}{\partial k_{x}}=0 .
$$

In the assumption of isotropy of the elastic matrix, the required parameters are determined from Eqs. (1) and (2) and are given by the bulk modulus $\mu$, bending stiffness $D_{s}$ of the $2 \mathrm{D}$ elastic interface layer and the ratio of longitudinal and transverse elastic waves in the matrix $V_{r e l}=v_{l} / v_{t}$ :

$$
\begin{gathered}
k_{x 0}=\left(\frac{\mu}{D_{s}}\right)^{1 / 3}\left(\frac{2 V_{r e l}^{2}}{V_{r e l}^{2}+1}\right)^{1 / 3}=\left(\frac{\mu}{D_{s}}\right)^{1 / 3}\left(\frac{2(1-\sigma)}{3-4 \sigma}\right)^{1 / 3}, \\
g_{x x}=-3 D_{s}^{1 / 3} \mu^{2 / 3}\left(\frac{2(1-\sigma)}{3-4 \sigma}\right)^{2 / 3},
\end{gathered}
$$

where $\sigma$ is Poisson's ratio in the polymer matrix.

Since $g_{x x}=E_{s} \varepsilon_{x x}$, where $\varepsilon_{x x}$ is the in-plane strain of the matrix, from Eq. (4) we get:

$$
\varepsilon_{x x}=-3 \frac{D_{s}^{1 / 3}}{E_{s}} \mu^{2 / 3}\left(\frac{2(1-\sigma)}{3-4 \sigma}\right)^{2 / 3} .
$$

For the monolayer graphene, we take bending stiffness $D_{s}=1.1 \mathrm{eV}$ [4]. For the low-density polyethylene, we take $\mu=0.2 \mathrm{GPa}, v_{t}=0.466 \mathrm{~km} / \mathrm{s}, v_{l}=2.400 \mathrm{~km} / \mathrm{s}$, and $V_{\text {rel }}=5.15$ [22]. We find from Eqs. (3) and (5) that the monolayer of graphene embedded in the matrix of low-density polyethylene undergoes periodic static bending deformation (modulation) with the wavelength $\lambda_{0}=2 \pi / k_{x 0} \approx 48.4 \AA$, triggered by the compressive strain in the matrix as small as $\varepsilon_{x x}=-2.5 \times 10^{-3}$. The bending modulation wavelength $\lambda_{0}$ is about 34 times larger than the carbon-carbon bond length $a^{*}=1.42 \AA$, that justifies the above description in the long-wavelength approximation.

\section{Results and discussion}

In Fig. 1 we present the change of the dispersion of surface acoustic waves, propagating along the $\mathrm{x}$ axis in the FLG embedded in soft matrix of low-density polyethylene, triggered by the compressive strain in the matrix along the $x$ axis. Frequency is measured in units of $v_{t} / a$, the wave vector $k_{x}$ is measured in units of $1 / a$, where $v_{t}=0.466 \mathrm{~km} / \mathrm{s}$, 


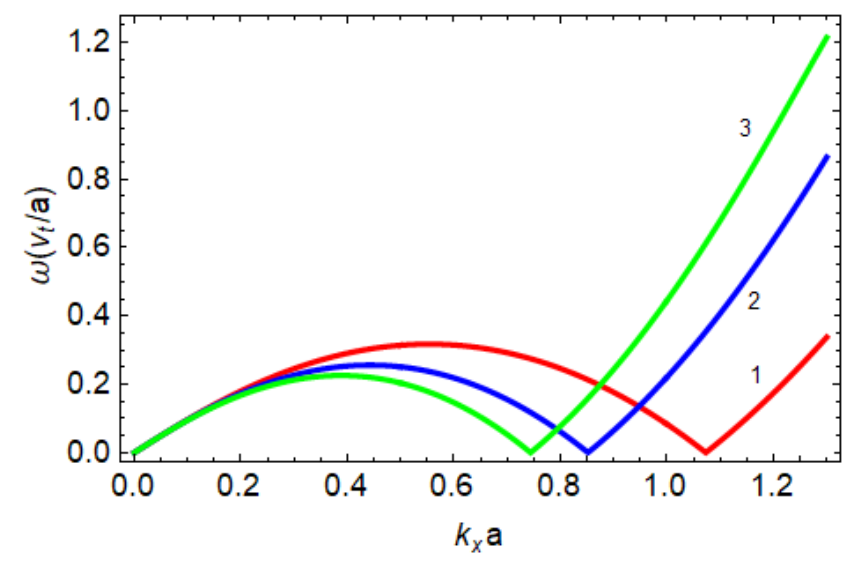

Fig. 1. Dispersion of flexural surface acoustic wave, propagating along the $\mathrm{x}$ axis in the few-layer graphene embedded in a matrix of low-density polyethylene, triggered by the compressive strain in the polyethylene along the $x$ axis. Frequency is measured in units of $v_{t} / a$, wave vector $k_{x}$ is measured in units of $1 / a$, where $v_{t}=0.466 \mathrm{~km} / \mathrm{s}$, $a=\rho_{s} / \rho=8.26^{x} \AA$ for the polyethylene with density $\rho=920 \mathrm{~kg} / \mathrm{m}^{3}$. Lines 1,2, and 3 correspond to the number of monolayers $n$ in FLG $n=1,2,3$, respectively. Compressive surface stress in the few-layer graphene is given by Eq. (4).

$a=\rho_{s} / \rho=8.26 \AA$ for the polyethylene with density $\rho=920 \mathrm{~kg} / \mathrm{m}^{3}$ [22]. In these simulations, we have assumed that $D_{s}^{(n)}=n D_{s}, E_{s}^{(n)}=n E_{s}$, and $g_{x x}^{(n)}=n g_{x x}$, with $n=1,2,3$. Both the wave numbers of periodic bending deformation, $k_{x 0}^{(1)}=1.07 / a, \quad k_{x 0}^{(2)}=0.849 / a, \quad k_{x 0}^{(3)}=0.742 / a$, and the value of the threshold negative surface stresses $g_{x x}$, given by Eqs. (3) and (4), are very well confirmed by the numerical simulations. In this model of weak interlayer bonding in FLG, the wave number of periodic bending deformation and the threshold compressive strain in the matrix decrease with the number of graphene layers in FLG as $k_{x 0}^{(n)}=1.07 /\left(a n^{1 / 3}\right)$ and $\varepsilon_{x x}^{(n)}=-2.5 \times 10^{-3} / n^{2 / 3}$, respectively, see Eqs. (3) and (5).

On the other hand, in the case of strong interlayer bonding in FLG the bending stiffness, effective 2D Young modulus and surface mass density of the layer of hexagonal crystal with thickness $h$ with free surfaces in $x y$ plane will be the following, see Refs. [23,24]:

$$
\begin{gathered}
D_{s}=\frac{h^{3}}{12}\left(C_{11}-\frac{C_{13}^{2}}{C_{33}}\right), \\
E_{s}=h\left(C_{11}-\frac{C_{13}^{2}}{C_{33}}\right), \\
\rho_{s}=h \rho .
\end{gathered}
$$

As follows from Eqs. (3), (5)-(7), in this case the threshold compressive strain in the matrix does not depend on $h$,

$$
\varepsilon_{x x}=-\frac{3}{(12)^{1 / 3}}\left(\frac{\mu}{C_{11}-\frac{C_{13}^{2}}{C_{33}}}\right)^{2 / 3}\left(\frac{2(1-\sigma)}{3-4 \sigma}\right)^{2 / 3},
$$

while the wavenumber at which the softening occurs decays with $h$ as $k_{x 0} \propto 1 / h$ :

$$
k_{x 0}=\frac{(12)^{1 / 3}}{h}\left(\frac{\mu}{C_{11}-\frac{C_{13}^{2}}{C_{33}}}\right)^{1 / 3}\left(\frac{2(1-\sigma)}{3-4 \sigma}\right)^{1 / 3} .
$$

In the considered case of the layer of graphite embedded in a matrix of polyethylene, which corresponds to the case of the layer of stiff hexagonal crystal embedded in a compliant soft matrix, the condition $k_{x 0} h \ll 1$, which is assumed in the model of layer bending instability, is satisfied due to the conditions $\mu \ll C_{11}$ and $C_{13}^{2} \ll C_{11} C_{33}$, see Eq. (10). Such substantial difference between the scaling of the control parameters $k_{x 0}^{(n)}$ and $\varepsilon_{x x}^{(n)}$ of the bending instability of FLG as functions of $n$, given by Eqs. (3) - (5) in the different models of interlayer bonding in FLG, can be used for the study of bending stiffness and 2D Young modulus of the embedded graphene nanolayers.

In conclusion, we have analyzed and numerically simulated the softening of flexural surface acoustic waves, localized in the plane of few-layer graphene embedded in soft matrix of low-density polyethylene, triggered by the compressive strain in the matrix. Softening of the flexural surface acoustic wave results in spatially periodic static bending deformation (modulation) of the embedded nanolayer with the definite wave number $k_{x 0}$. We have considered FLG consisting of one, two, and three monolayers of graphene, and have described the different models of interlayer bonding of graphene monolayers in a few-layer graphene, which correspond to the weak and strong interlayer bonding. Both the wave number of periodic bending deformation $k_{x 0}$ and the value of the threshold negative surface stress $g_{x x}$, given by Eqs. (3) and (4), are very well confirmed by the numerical simulations. The bending instability of FLG can be used for the study of bending stiffness and 2D Young modulus of the graphene nanolayers, embedded in a strained compliant matrix.

Acknowledgements. The work of Yu.A. K. and I.A. S. was supported by the Russian Science Foundation in the part of the study of the dispersion and modulation wave number of soft surface acoustic wave in few-layer graphene (Grant No. 16-13-10302). The work of A. A. K. was supported by the Russian Foundation for Basic Research in the part of the study of scaling relations for bending stiffness and Young modulus of few-layer graphene (Research Project No. 17-32-50097mol_nr).

\section{References}

1. A. K. Geim. Science. 324, 1530 (2009).

2. C. Lee, X. Wei, J.W. Kysar, J. Hone. Science. 321, 385 (2008).

3. J.S. Bunch, S. S. Verbridge, J. S. Alden, A. M. V. D. Zande, J. M. Parpia, H. G. Craighead, P. L. McEuen. Nano Lett. 8, 2458 (2008).

4. T. J. Booth et al. Nano Lett. 8, 2442 (2008).

5. F. Guinea, M.I. Katsnelson, A. K. Geim. Nat. Phys. 6, 30 (2010).

6. E. A. Korznikova, S. V. Dmitriev. Journal of Physics D: 
Applied Physics. 47(34), 345307 (2014).

7. A. V. Savin, E. A. Korznikova, S. V. Dmitriev. Phys. Solid State. 57(11), 2348 (2015).

8. A. V. Savin, E. A. Korznikova, S. V. Dmitriev. Phys. Rev. B. 92(3), 035412 (2015).

9. E. Barani, I. P. Lobzenko, E. A. Korznikova, E. G. Soboleva, S. V. Dmitriev, K. Zhou, A.M. Marjaneh. Eur. Phys. J. B. 90(3), 38 (2015).

10. A.V. Savin, E.A. Korznikova, S.V. Dmitriev, E. G. Soboleva. Computational Materials Science. 135, 99 (2017).

11. Yu. A. Kosevich, L.G. Potyomina, A.N. Darinskii, I. A. Strelnikov. Phys. Rev. B. 97, 094117 (2018).

12. H.J. Allen. Analysis and Design of Structural Sandwich Panels. Pergamon, Oxford (1969) 283 p.

13. Yu. A. Kosevich, E. S. Syrkin. Phys. Lett. A. 122, 178 (1987).

14. Yu. A. Kosevich, E. S. Syrkin. Sov. Phys.-Solid State. 29, 1825 (1987).

15. Yu. A. Kosevich, E. S. Syrkin. Sov. Phys.-Crystallogr. 33,
801 (1988).

16. L.D. Landau, E.M. Lifshitz. Theory of Elasticity. Pergamon, Oxford (1986).

17. S. Scharfenberg et al. Appl. Phys. Lett. 98, 091908 (2011).

18. P. N. Keating. Phys. Rev. 145, 637 (1966).

19. F. H. Stillinger, T.A. Weber. Phys. Rev. B. 31, 5262 (1985).

20. A. V. Savin, Y.S. Kivshar, B. Hu. Phys. Rev. B. 82, 195422 (2010).

21. K. V. Zakharchenko, J.H. Los, M.I. Katsnelson, A. Fasolino. Phys. Rev. B. 81, 235439 (2010).

22. M.D. Lechner. In: Springer Handbook of Condensed Matter and Materials Data (Ed. by W. Martienssen and H. Warlimont). Springer, Berlin (2005) 1200 p. Polymers. P. 477.

23. Yu. A. Kosevich, E. S. Syrkin. Low Temp. Phys. 9, 616 (1983).

24. E.S. Syrkin, S.B. Feodos'ev, K.V. Kravchenko, A. V. Eremenko, B. Ya. Kantor, Yu. A. Kosevich. Low Temp. Phys. 35, 158 (2009). 